\title{
ARAUCO REVIVE UN RITO DE MUERTE
}

"Puerto Saavedra. - un mapuche entregó su nieto en guillatún que rogaba contra los movimientos sísmicos. El niño -de apenas 5 de edad- fue despedazado y lanzado al mar. Jurisprudencia exime de responsabilidad a los autores del crimen.

(Por nuestro enviado especial, Marcos de la fuente).

Una ola de indignación recorrió Chile cuando se supo la noticia. Los indígenas de Loncopulli, una localidad cercana a Puerto Saavedra, en la provincia de Cautín, sacrificaron un niño de seis años a sus dioses. El "sacrificio ceremonial" fue realizado el viernes 5 de junio por la "machi" de Puerto Saavedra, María Juana Namoncura y sus ayudantes Juan Paiñán Huenchumán, Julio Painecur Cuminao y Juan José Painecur Paineo. El niño de seis años, José Painecur Painecur fue arrastrado por esta familia de hechiceros a la orilla del mar, muerto a golpes y abierto en canal, para arrancarle el corazón y

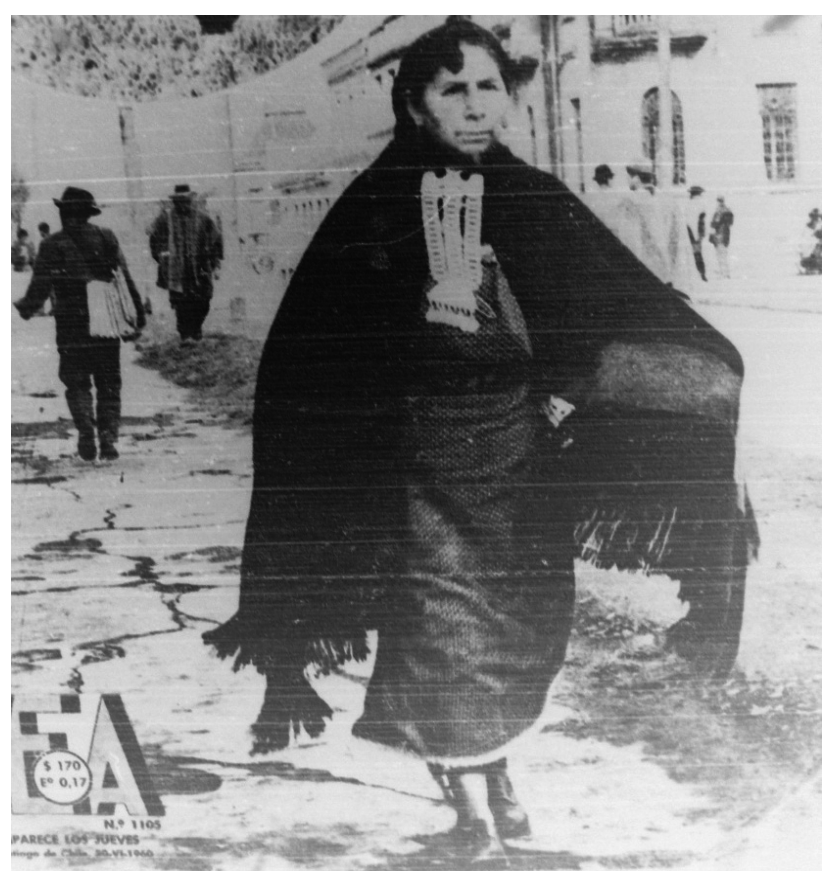
demás vísceras, las que fueron arrojadas al mar para calmar la ira de los dioses y terminar con los terremotos y maremotos.

Los "brujos" fueron detenidos por carabineros de Puerto Saavedra. Al ser trasladados a la ciudad de Nueva Imperial para ser juzgados, fueron casi linchados por la indignada población. Tres carabineros y seis soldados protegieron la vida de los hechiceros. Pero la ira popular logró vencer en parte la protección policial, y los golpeó hasta dejarlos inconscientes, con la cabeza y el cuerpo semidestrozados.

El antropólogo de la Universidad de Chile, Alberto Medina, se trasladó desde Santiago a Nueva Imperial para verlos. Quería conversar con los mapuches. Quería 
saber cómo y por qué realizaron el sangriento "guillatún" con sacrificio humano. Los encontró en el calabozo fuertemente atados; semiinconscientes y gravemente heridos.

No podían hablar.

Este maltrato ha movido a los dirigentes araucanos, quienes han recurrido a la prensa y a sabios como Alejandro Lipschutz, para que investiguen desde el punto de vista científico, antropológico este hecho que rebasa el frío articulado del Código Penal.

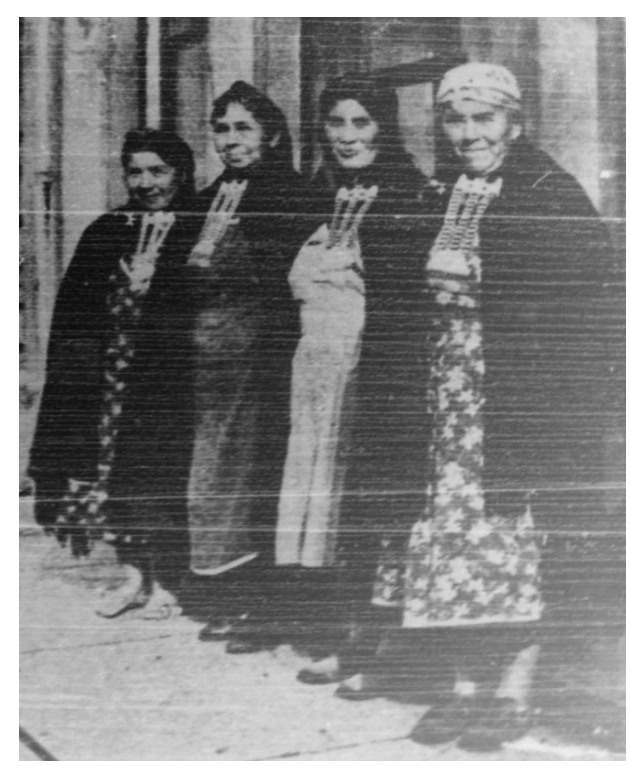

El cataclismo que hundió parte del territorio chileno en el mar, hizo emerger, al mismo tiempo, los milenarios rituales con sacrificios humanos en el grupo más atrasado de la reducción indígena de Cautín. De los 137 mil indígenas que pueblan la zona sur, los de Loncopulli son los que conservan los más primitivos sistemas de vida. Para ellos, el sacrificio ceremonial de ofrecer un niño en un holocausto a sus dioses no constituye una aberración ni un crimen. Es una ceremonia religiosa, simplemente.

Cuando ocurrió el terremoto del 21 de mayo, y el nuevo terremoto y maremoto del 22, los calafquenches hicieron sonar sus "cultrunes" (tambores), convocando a sus hermanos a celebrar "guillatunes" de tres días de duración, para aplacar las iras Huenu-Chao, el dios que castiga y otorga recompensas.

El jueves 26 de mayo, los indígenas de Puerto Saavedra subieron en largas filas, cantando y rogando a su dios, desde el destruido pueblo de Puerto Saavedra hasta los cerros. Todos vestían de blanco y rodeaban un buey blanco. Estaban rogando por que llegaran mejores días, y para ello el ritual exige el color blanco. Si no hubieran encontrado un buey de ese color, lo habrían disfrazado, colocándole en sus lomos telas blancas. El color negro en sus vestiduras y en el animal lo utilizan en sus rogativas cuando necesitan lluvias y para sus trabajos agrícolas. Los guillatunes se prolongaron durante tres días, en los que no dejaron de sonar los cultrunes machis.

Fue, seguramente, cuando estas rogativas demostraron que no podían contener la ola de temblores, lluvias y calamidades, que los indígenas de Loncopulli decidieron probar sus antiguos ritos, cuyas raíces se hunden en la edad de piedra. 


\section{¿QUÉ VA A PASAR?}

"La fuerza irresistible que contempla el No 9 del artículo 10 del Código Penal, como circunstancia eximente de responsabilidad, no comprende solo la coacción física, sino que también la de carácter psicológico, sea que ésta proceda desde el exterior hacia el fuero interno del sujeto, sea que provenga de su propia psiquis".

El legislador y los tribunales de justicia chilenos no han dejado jamás de comprender las condiciones de atraso en que vive el indígena chileno. Nuestra jurisprudencia está saturada de ejemplos. El último caso se vio a fines del año 1953, en la Corte de Valdivia. Una joven mapuche había confesado ser la autora de un homicidio brutal. Un homicidio donde la víctima era su propia abuela. El crimen había sido cometido a golpes de piedra y con un epílogo asqueroso la joven homicida le succionó la sangre a su víctima.

En la sentencia después de una minuciosa investigación en la que participaron estudiosos y hombres de ciencia, la juez María Mardones Montenegro determinó:

"Está exenta de responsabilidad penal, por haber actuado bajo el imperio de una fuerza psíquica irresistible, una india mapuche, procedente de una tribu carente totalmente de cultura, que da muerte a otra a quien ella y todos los demás del ambiente reputaban bruja, dotada de poderosas artes maléficas y que, en la convicción de la reo le había ya causado y le iba a causar en el futuro graves daños que podrían significar la pérdida de la vida. La reo ha sido incapaz de obrar con libertad e inteligencia frente al imperativo de su propia conservación, amagada por actividades de la occisa que estimaba capaces de dañarla".

\section{HABLAN LOS INDIGENISTAS}

A raíz del proceso seguido contra Juana Catrilaf, la joven mapuche que asesinó a su abuela, una comisión de indigenistas estudió el caso y emitió un minucioso informe. Esta comisión estuvo integrada por el teniente coronel Gregorio Rodríguez, por el sabio Alejandro Lipschutz y por el doctor Rigoberto Iglesia. Los peritos invocaron en el informe de maras una gran cantidad de experiencias históricas y étnicas.

Desde luego, la creencia en el poder mágico y maléfico del curandero, que al mismo tiempo es hechicero y brujo, ha sido general en todos los pueblos primitivos. Probablemente, es aun más generalizada la creencia en la bruja maléfica. La hechicería o brujería no escapa ni al Antiguo Testamento, en él se ordena 
su muerte: "A la hechicera no dejarás que viva", Éxodo 22, 18. Pero al mismo tiempo, la brujería es auténtica realidad para la iglesia cristiana y hasta para pensadores como Tomás de Aquino. En Europa, la brujería ejerce gran influencia hasta el siglo XVIII. Las últimas ejecuciones públicas de brujas tuvieron lugar en Sevilla en 1781. En Alemania se seguía decapitando brujas en 1793. En el siglo XVI un célebre médico alemán publicó un libro contrario a la creencia en brujas, causando la indignación popular que casi terminó con su vida en la hoguera. En Chile existe un ejemplo famoso personificado en doña Catalina de los Ríos y Lisperguer: la Quintrala -importante dama de la sociedad colonial chilena, que ofició artes mágicas impresionantes. Tomás Guevara, educador e investigador chileno, puntualiza en su obra "Chile Prehistórico":

"La idea madre en el conjunto de nociones supersticiosas del araucano se halla en la magia. Para ponerse en comunicación con los espíritus benefactores y neutralizar la acción de los males, para extraer del cuerpo humano los hechizos y pronosticar el porvenir, ha tenido que proveerse el mago de fórmulas cabalísticas de manipulaciones y efectos secretos, cantos evocadores y danzas sagradas. Tales operaciones y operadores forman los elementos de la magia araucana".

Tomás Guevara en la página 114 de su "Chile Prehistórico" advierte:

"Desde la época precedente a la conquista española hasta hoy mismo, los araucanos han concebido la enfermedad no como debida a causas físicas, sino a maleficios exteriores u objetos extraños que se introducían en el cuerpo a fin de perturbar las leyes biológicas. Podía manejar esos medios de cultivo cualquier persona contra sus enemigos y particularmente los brujos destructores infatigables de la vida humana. Pero el agente más activo era y es la fuerza o influencia maligna tan esparcida en el territorio araucano que los indios del norte llamaron "huecube" y los del sur "huecufe". Se exteriorizaba esta fuerza destructora, a menudo, en flechas diminutas que herían el corazón u otro órgano da la víctima, según la creencia secular".

Los manipuleos mágicos que realizaban los indígenas chilenos para curarse las enfermedades, para anular los males de la colectividad, para neutralizar las fuerzas de la naturaleza, diluvios, sequías, movimientos sísmicos, etc., se llaman, en su lengua, machitun o machitucar. El padre Félix de Augusta en su obra "Lecturas Araucanas", explica: "se da el nombre de machi o fileu a ciertas personas indígenas que desempeñan el oficio de curandero y cuya arte se apoya en la suposición de 
que todas las enfermedades interiores son producidas por un mal influjo misterioso. Estas machis se dan aire de sacerdotisas y se creen más nobles que todos los araucanos".

De las funciones de machi es inseparable el canto y la danza acompañados del toque de caja (cultrún). En la mayoría de las canciones el tema es la promesa de la bruja de anular el mal. A veces, la machi se aventura a indicar la causa del maleficio. Esta sacerdotisa se hace pagar sus intervenciones en dinero o con animales. A éste respecto Tomás Guevara afirma: "El precio que se paga por un machitún, en primer lugar, depende de la fortuna del enfermo, de la forma que abona a la curandera, fluctúa entre diez presos y un animal (escribe esto en 1929)".

Todos los estudiosos coinciden en que ahora mismo se nota entre los araucanos un vestigio de su mentalidad antigua acerca de las enfermedades, la muerte, los espíritus, el parentesco, los sueños, la producción de la lluvia, la fuerza mágica de muchos fenómenos. Guevara dice que "el número de brujos que existe y ha existido en la Araucanía es asombroso". A su turno, el padre Félix de Augusta, agrega: "Las machis continúan con sus supercherías, riéndose no pocos indígenas de ellas. Vengan a establecerse cerca de ellos, buenos médicos que pidan honorarios médicos, entonces dichas machis quedarán aún más abandonadas de lo que están hoy día, pero siempre quedarán algunas, pues la estupidez nunca se acabará del todo". Tomás Guevara asegura que "estudiantes de la Escuela Normal mantienen aún restos de sus creencias primitivas".

En la actualidad contribuyen a formar juicios sobre la supervivencia en grupos de indígenas que viven aislados de las costumbres y creencias sobrenaturales de sus antepasados, los numerosos actos rituales que se desarrollan en nuestro sur. Tales como, las juntas ("guillatunes"), los parlamentes (aunque ya simbólicos), etc.

\section{LA JURISPRUDENCIA}

Se entiende por imputabilidad "la capacidad genérica de obrar en derecho penal (estado potencial)" o "la posibilidad, condicionada por la salud y la madurez espirituales del autor, de valorar correctamente los deberes y obrar conforme a su convencimiento". Otros autores opinan que la imputabilidad está condicionada a la "capacidad de conducirse socialmente".

Nuestro Código Penal se inspira en que la imputabilidad surge como consecuencia de que el hecho punible haya sido voluntario. Consecuencia de esto es que no solamente de la pena o castigo, sino que también del Derecho Penal, quedan totalmente excluidos aquellos sujetos que cometen un delito en condiciones de 
alteración de sus facultades mentales, que les priven de capacidades de comprender y determinarse.

Hacía más de veinte días que temblaba a cada momento y ya nadie sabía ni intentaba presumir lo que iba a pasar. Dos terremotos habían sacudido nuestro aporreado Sur. Hasta el mar se había salido arrasando lo poco que quedaba, permaneciendo después con un rugido amenazante que prometía de todo. Ya no se lloraba por las pérdidas, se gemía por la incertidumbre. En Nueva Imperial -cabecera del Departamento ubicado al noroeste de Cautín, bastón del indigenismo chileno- se registró un diálogo ingenuo, pero estremecedoramente macabro. Por las calles de la ciudad, la gente corría en una danza de dolor y muerte. Unos lloraban a su padre anciano aplastado por un murallón, otros sollozaban por el hijo arrebatado por el mar. Y en un caserón semidestruido, donde antes funcionó una escuela pública, el profesor y dirigente indígena Heriberto Manquilef escuchaba perplejo la denuncia de un niño ciego, Lorenzo Painemila Caripán, de la reducción Conim, que le decía:

-"Nos han robado los dos caballos, peñi (amigo). Acompáñenos a dar cuenta donde el señor gobernador. Los ladrones son de la reducción de Colillufú. Esos pillos robaron los caballos para comérselos en el guillatún... en ese guillatún en que mataron un niñito y lo arrojaron al mal...".

\section{PRIMERAS PESQUISAS}

Para llegar a la reducción de Collileufú, desde Nueva Imperial, hay que atravesar una extensa región inundada por la acción del lago Budi y el mal Collileufú está ubicado a $9 \mathrm{Km}$. de Puerto Saavedra, entre esta localidad y el lago Budi.

Conocida la noticia en la ciudad por boca del niño mapuche que había perdido sus caballos, se trasladó hasta el sitio del suceso el teniente de Carabineros Mario Urrutia Elgueta. No hubo necesidad de mayores indagaciones. Los indígenas contaron detalles del horrible sacrificio sin demostrar el menor arrepentimiento. Al contrario, se mostraban muy neutrales, conformes y hasta contentos.

Ninguno de los sindicados como autores materiales del crimen trató siquiera de huir. Al oficial de Carabineros respondieron con aire de orgullo, como si tuvieran conciencia de un deber cumplido.

Según las narraciones, el domingo 5 último, a 15 días del comienzo del cataclismo, los integrantes de la reducción mapuche Collileufú continuaron en sus rogativas para aplacar al dios del mal que había destrozado a sus habitaciones y agrietado sus campos en forma despiadada. Poco antes de las siete de la tarde, mientras los hombres danzaban al son de sordos tambores, la machi Juana María Namencura Añén 
caía en "éxtasis" con un sueño saturado por el alcohol de un brebaje de maíz, "el muday". En el parte policial se cuenta que el sacrificio del niño fue fraguado en nerviosos minutos de silencio. De un silencio impresionante. Al incorporarse la "machi" estallaron de nuevo los tambores y luego otro silencio para escuchar a la bruja que daba una orden dirigiéndose a Juan José Painecur Paineo:

-"Vete corriendo y tráeme un niño..., ni pequeño ni grande... para sacrificárselo al dios nuestro para que calme la mar y los temblores".

Escuchar el mandato divino y correr a cumplirlo, fue una sola cosa para Juana José Painecur Paineo. Sin embargo, al llegar a la casa de su hija (la Rosa) en busca del nieto que había que sacrificar, un hálito de humanidad le nubló la vista y estuvo a punto de desobedecer. Su hermano mayor debió darle el empujón de gracia.

Antes de las 8 de la noche, la machi y los mapuches que danzaban en torno suyo tenían en sus manos al niño José Painecur Painecur, de 6 años de edad. A las nueve de la noche, el cuerpo del niño ya estaba despedazado con el corazón en las manos de la machi y con varios órganos lanzados al mar.

\section{JUSTICIA Y BARBARISMO}

Cuando el juez de Letras de Nueva Imperial se enfrentó a la "machi" Juana María Namencura Añén, y le preguntó que no había sacrificado un animal en lugar de un despresar a un niño, la mapuche le respondió con tono golpeado:

-"Tú tienes que saber que para un grande mal se emplea un remedio muy grande. ¡Animales era muy poca cosa...! ¡Temblor mucho...!”.

Junto con la "machi" fueron detenidos tres hombres y una mujer. Todos ellos confesaron libre, espontánea y casi orgullosamente su participación en el crimen.

El ancestral pavor a las fuerzas desatadas por la Naturaleza había despertado el salvajismo religioso de sus antepasados. Cinco mapuches, analfabetos todos, participaron en el asesinato. Tras las rejas de la cárcel, ninguno de los protagonistas activos del crimen se siente arrepentido. Todos estaban seguros de haber cumplido con su deber.

\section{UN POCO DE HISTORIA}

Para el indígena, hombre que ha sufrido a través de muchas generaciones los ataques de la naturaleza y las embestidas de otros hombres más civilizados que han pretendido someterlos, muchas fuerzas y fenómenos escapan de su comprensión racional para caer en el terreno de los mitos. Desde antaño, el araucano dotó a la 
naturaleza circundante con atributos físicos y con volición. Si salía de caza, por ejemplo, recordaba que una vez, al salir de su choza, encontró una piedra que luego lanzó al río vecino, y que el regreso de la jornada fue difícil por el gran número de animales capturados. Desde entonces, el encontrar una piedra y tirarla al río era elemental para tener éxito en la caza. Cuando por una infeliz distracción olvidaba lo de la piedra, ya en medio del terreno de la caza recordaba el olvido y se sugestionaba de tal forma que desperdiciaba oportunidades, seguro que debía fracasar en esa jornada. El hombre primitivo no raciocina. Observa solamente las consecuencias de ciertos fenómenos y repite como ritos aquellos actos que le han traído éxito en sus empresas.

Arauco revive un rito de muerte Revista Vea, 30 de junio, 1960. 